\title{
Amish and Mennonite Lay Caregivers' Experiences Using the B\&W Burdock Leaf Treatment on Burns and Wounds: A Qualitative Study
}

\author{
Rosanna F. Hess, RN, DNP \\ Adjunct Faculty, Instructor of Nursing \\ School of Nursing \& Health Sciences \\ Malone University
}

\begin{abstract}
Amish and Mennonites have a long standing heritage of caring for each other within the community and family setting using natural, herbal medicines and therapies. For several decades, in numerous Anabaptist communities across the United States, a burns and wounds treatment has been popularized by the training of hundreds of lay caregivers. Little is known outside these communities about the experiences of these caregivers dedicated to providing burns and wounds care. The aim of this study was to describe the lived experience of caregivers who use the Burns $\&$ Wounds ointment $(\mathrm{B} \& \mathrm{~W})$ and burdock leaf treatment. Twelve caregivers (eight women and four men) who provide care in five states were interviewed. They ranged in age from 34 to 55 years with eight to 12 years of care. Data were analyzed manually by content analysis. Four major themes provide a rich, in-depth description. Rewarding work with heavy responsibility and decisive action then waiting to heal are accounts of personal commitments to caregiving. Selfreliance along with collaboration portrays family and community involvement. Treatment disallowed versus negotiated support describes caregivers' interactions with health care professionals. The use of the B\&W burdock treatment is embedded in the cultural beliefs of these lay caregivers attending to their own, using natural products when possible, while respecting health care professionals' knowledge and abilities. They believe their treatment reduces the need for skin grafts, high doses of analgesics, and cost. Their wish is for medical supervision of their patients, including vital signs and hydration, while they provide wound care.
\end{abstract}

\section{Keywords}

Health care professionals; Community-based care; Herbal remedy; Non-conventional burn care; Skin grafting 


\section{Introduction}

Since the mid-2000s several Amish leaders have popularized a treatment for burns and wounds using Burns \& Wounds Ointment (B\&W) and burdock leaves. Developed and propagated in the 1990s by John Keim, an Amish man, this remedy is now used by thousands of Amish and other Anabaptist households throughout the United States and Canada. Hundreds of Amish and other interested people have been trained to use this therapy (Burn Certification 2008 ) and serve as community-based caregivers. When requested by burned and injured victims or their families, these caregivers also provide treatment to hospitalized patients if the caregivers are permitted by the medical facility. Little is known outside those communities about the experiences of Amish and Mennonite caregivers dedicated to providing burns and wounds care. The aim of this study was to describe the lived experience of caregivers who use the $\mathrm{B} \& \mathrm{~W}$ burdock leaf treatment while caring for patients who have been burned or injured.

$\mathrm{B} \& \mathrm{~W}$ ointment is an organic, vegetable-based product prepared in Ohio by Holistic Acres, LLC. It is also produced by HDM Topicals and marketed under the name of RegenaDerm ${ }^{\mathrm{TM}}$. This ointment contains honey, aloe vera gel, lanolin, wheat-germ and olive oils, beeswax, marshmallow root, Lobelia inflata, comfrey, white oak bark, myrrh, wormwood, and vegetable glycerin (Amish Burn Study Group, et al. 2015; Trinkle 2016). Burdock (Arctium spp) roots, seeds and leaves have been used in traditional medicine for centuries in Asia, Europe, and the Near East (Chan, et al. 2011). Burdock leaves are known to have analgesic, antimicrobial, and anti-inflammatory properties (Fujita, et al. 1995; Lou, et al. 2010; Erdemoglu, et al. 2009).

To prepare a dressing using the $\mathrm{B} \& \mathrm{~W}$ burdock leaf treatment, room-temperature $\mathrm{B} \& \mathrm{~W}$ ointment is stirred to a creamy texture and then applied to the shiny side of softened burdock leaves. The ointment side of the leaf is then placed on the burn or wound, covering the edges. The leaf dressing is then covered with gauze to keep it in place. A thick gauze pad is secured as a covering over the gauze wrap to serve as a semiocculsive bacteriostatic moisture barrier (Flurry, et al. 2017). Dressings are removed and changed every 12 hours. While the wound is uncovered the caregivers gently debride it with $4 \times 4$ gauze squares dipped in slightly warmed coconut oil. Burns are never scrubbed. Burdock leaves alone are sometimes wrapped as a poultice on sprains or bruises (Fujita, et al. 1995). Other procedural details and examples are reported by Flurry, et al. (2017), Main, et al. (2012), and Amish Burn Study Group, et al. (2015).

\section{Literature Review}

The use of B\&W and burdock leaves on hospitalized patients has been described in the literature. Flurry, et al. (2017) did a retrospective chart review on six Amish or Mennonite patients with severe, complex, traumatic wounds caused by garden or farm machinery. They concluded that this treatment, though unconventional, did not harm the patients who all eventually healed without skin grafting. Patients and families appreciated that they were allowed to use the B\&W burdock leaf remedy and avoid skin grafting. Lee and Ruth-Sahd (2011) cared for a 44-year old man injured in a farm accident. His family requested the use of burdock leaves. The hospital staff worked together with the patient and his family to provide the care they desired with a positive outcome and a new level of respect and trust between the staff and Amish community. Kahn, et al. (2013) described a case that posed a serious ethical dilemma for the medical and nursing staff. The family of a 25 -year old man with $75 \%$ of his body burned 
requested permission to have an Amish burn caregiver use the B\&W burdock leaf treatment based on this man's previously declared preferences. After several meetings between the family and the medical staff, all agreed to a 'shared treatment'; the hospital staff provided analgesic and intravenous care and the family and community caregiver did the burn care. The patient did not survive. The hospital staff respected the patient's and family's wishes but also experienced anxiety and anguish when they could not provide what they believed to be optimal care. A description of the experience and reactions of the Amish caregivers was not included in that case report.

Use of B\&W burdock leaf treatment has also been described on non-hospitalized patients. Outcomes of a pilot study of five patients in Ohio with burns over less than $5 \%$ of body surface who were seen by physicians or nurses in an emergency department showed there were no infections, healing times were comparable to conventional burn care, and the need for pain medications during dressing changes was minimal (Amish Burn Study Group, et al. 2015). Main, et al. (2012) conducted a survey of Anabaptist communities who used this treatment in their homes. Thirty-two respondents described care of mild to severe burns with limited pain, rapid healing, and minimal scarring. They appreciated the non-stick dressings created by the burdock leaves. They preferred this home remedy because they were far from health care providers and did not use health insurance.

\section{Methods}

\section{Design}

To describe the experiences of lay Anabaptist burn caregivers using the B\&W burdock leaf treatment, a qualitative research approach was used. Ethics review and approval was provided by the Human Research Committee at Malone University, Canton, OH. A letter of support, written by the leader of a burn care team in Ohio, accompanied the application for ethics review.

Participants signed a consent form.

\section{Participant Recruitment}

Purposive sampling was used to recruit active Amish and Mennonite burn caregivers. Initial recruitment took place during the 2016 Amish Caregivers Seminar in Mt Hope, Ohio. Over 100 caregivers were in attendance. The researcher was a guest speaker at that meeting and received permission from the organizers to present the proposed study and to ask for volunteers. At the conclusion of the meeting, 16 people asked for the consent form and interview guide. The researcher sent reminder letters with study documents to those volunteers several weeks later. Eight responded either with signed consent forms and written responses or contacted the researcher saying they would be available for a phone call or personal visit. Over the ensuing months, the researcher drove to caregivers' homes in four states to conduct interviews. She also phoned other potential participants explaining the study's objectives and procedures. 


\section{Figure 1: Interview Guide}

- Explain how you got involved in providing burn/wound care.

- Describe the training you received to do burn care.

- Explain your preference of burdock leaves and B\&W ointment for burn care.

- What other ointments or therapies do you incorporate?

- What is your opinion about skin grafting and rationale for or against it?

- What advice do you give patients (families) about nutrition?

- How do you involve family in the care?

- Explain what it's like to take care of burn-injured and wounded people.

- Tell me why you volunteer to take care of these patients.

- How do you work with other caregivers?

- Tell me about the challenges and obstacles you have faced while doing burn care and how you have overcome them.

- Describe one burn-injured person that you have cared for that stays in your memory, and why.

- Add other details that you would like to include.

\section{Data Collection}

Data was collected using a structured interview along with probing questions. The interview guide was constructed by the researcher based on her previous six years working with Amish burn caregivers on other projects and on a review of burn care research literature. Interview questions are listed in Figure 1.

Three caregivers participated by sending their handwritten answers in the mail, preferring not to be tape-recorded. Eight participants were interviewed face-to-face in the caregivers' homes; one person participated by phone. These nine people agreed to have their interviews audio-recorded. See Table 1 for details. Recruitment was discontinued on the principle of data saturation, when redundancy of information was achieved (Polit and Beck 2012).

\section{Data Analysis}

Audio-recorded interviews were transcribed verbatim. Analysis was conducted manually using qualitative content analysis (Polit and Beck 2012). Transcripts were read and reread. Data were refined into smaller units by extracting key statements and words from each transcript individually. Significant phrases were then given codes or conceptual names. These coded units were then blended based on thematic similarities. Themes are substantiated in the text below with in-depth descriptions and unredacted quotes from participants. Confidentiality is maintained by not identifying the origin of the quotations.

\section{Scientific Rigor}

Several steps were taken throughout the study process to establish credibility of the findings. The author spent many hours with Amish caregivers discussing various aspects of 


\section{Table 1: Description of Burn Caregiver Participants}

\begin{tabular}{c|c|c|c|l} 
Gender & Age & Residence & Experience** & Interview Method \\
\hline F & 54 & Kentucky & $8 \mathrm{yrs}$ & Handwritten answers \\
F, M* & 43,46 & Ohio & $9 \mathrm{yrs}$ & In-person, audio-recorded with field notes \\
F, M* & 55,54 & Indiana & $10 \mathrm{yrs}$ & In-person, audio-recorded with field notes \\
$\mathrm{M}$ & 34 & Ohio & $12+\mathrm{yrs}$ & Phone, audio-recorded with field notes \\
$\mathrm{F}$ & 48 & Tennessee & $9 \mathrm{yrs}$ & Handwritten answers \\
$\mathrm{F}$ & 53 & Pennsylvania & $9 \mathrm{yrs}$ & In-person, audio-recorded with field notes \\
F, M* & 43,43 & Pennsylvania & $9 \mathrm{yrs}$ & In-person, audio-recorded with field notes \\
$\mathrm{F}$ & Unknown & Kentucky & $8 \mathrm{yrs}$ & Handwritten answers \\
$\mathrm{F}$ & 52 & Pennsylvania & $9 \mathrm{yrs}$ & In-person, audio-recorded with field notes \\
\hline
\end{tabular}

*Husband and wife interviewed together

**Years of experience at time of interview does not equate to actual experience since some caregivers had taken care of many more patients than others

Amish culture and burn caregiving. She attended meetings of burn teams at local, regional, and national levels. She observed burn care on several occasions including in the hospital. To validate the findings, the researcher met with several burn caregivers who were not participants in the study to review anonymous quotations and subsequent themes that had been developed. Those caregivers recognized their own experiences within the themes, with slight variations of opinion. This added authenticity to the study's findings.

\section{Results}

\section{Description of Sample}

Twelve people - three married couples and six individuals (eight women and four men total) from five states - participated in this study. The participants ranged in age from 34 to 54 years, with an average age of 47.7 years; and an average of 8.6 years of burn caregiving experience. See Table 1 for details.

\section{Types of Burns and Wounds}

During the interviews the caregivers described various types of burns and wounds they treated with the B\&W burdock leaf therapy. Most of the burns were relatively small, under 5\% of body surface. Most frequently mentioned were hot liquid burns from coffee, tea, boiling water, tomato juice, and contents of a crock-pot. When asked to describe memorable cases, they spoke of burns caused by falling into fire pits and from explosions. A non-Amish man asked for help for his hand that was partially blown off from what they found out later was an explosion of a meth lab in his house. The caregivers also described the use of B\&W and burdock leaves on diabetics with foot ulcers and a child whose toes had been caught in the spokes of a bicycle wheel. The caregivers used burdock leaves as a poultice on swollen knees, ankles, and other parts of the body that did not have open wounds. They never placed plain burdock leaves on open wounds. 


\section{Caregiver Themes}

Four major themes, with quotations, provide a rich, in-depth description of Amish and Mennonites' experiences as caregivers of burns and wounds. The first two themes, rewarding caregiving with heavy responsibility and decisive action then waiting to heal are accounts of personal commitments to caregiving. The third theme, self-reliance along with collaboration, portrays family and community involvement. The fourth theme, treatment disallowed versus negotiated support, describes caregivers' interactions with health care professionals who may or may not permit lay people to work with hospitalized patients.

\section{Rewarding caregiving with heavy responsibility}

Most of the participants became caregivers because someone in their family or settlement had suffered from burns or wounds. They were all trained by John Keim and his team of instructors. They were taught to cool burns, prepare the leaves, apply the ointment, wrap dressings, be alert for indications of pain and infection, and gauge the healing progress. They also counsel patients and family members on proper nutrition to promote healing. When asked why they volunteered to take care of people with burns and wounds several caregivers expressed how rewarding their work was. One woman said,

It is very rewarding to see the relief of pain. And years later meet a child, and they still smile and talk to you. It's also humbling of how thankful they are. I've always taken on helping to heal injuries and burns and feel I can help someone in 'my little corner of the world.'

On the other hand, the caregivers recognized the gravity of their work. One woman said that she constantly thought about her cases, how she could improve the care she was providing.

If something goes wrong I'm always thinking what I could do better. What I could do to make it better, how I could do [dressing changes] with less pain, less anything. Sometimes we run into problems, and I'm always thinking about that without even knowing it. And I'll think, that's what I should be doing. That way, trying to think, I don't know. I get too involved.

The caregivers know that family members are depending on them to make the right decisions. One man said,

If there's one thing that keeps me up at night, it's the responsibility of making that decision about whether the person needs medical care. That is a big responsibility and I have to make [the decision]. The parents decide on what we tell them. And that's a big responsibility.

Caregivers know that severe burns and wounds could require knowledge and skills beyond their abilities. Several participants acknowledged their reliance on God to shoulder this responsibility. Two caregivers described how they prayed when caring for patients.

With the big burn I was describing, that diabetic person, I just, I felt so overwhelmed. I just felt I couldn't do anything until _ before I left [to go do the dressing changes], I just went somewhere and prayed for her. I just feel like I couldn't do it by myself, you know.

When you get somebody in and he's serious, and uh, you know that, and they are, you know, they're in your hands, and you're responsible for them, that is a big load. And I think it's, it's uh, it's something that you can, I mean, we can do it, but it's very hard. It's very hard for us. It's real, it's very hard for us to uh, to, you know, get through it. And we sure ain't out there looking for [people with 
burns]. [To face it] we, I usually go and talk to [another caregiver]. And then we, uh, pray a lot. Yes absolutely. That's the only Healer there is anyway. Don't matter what you put on, if He is not in and with you, you will never heal it. So that is one thing that we really do a lot, is praying that He will, you know, provide us with the right set of mind to keep, you know, to make sure we do everything right. And we, um, just try to be very cheerful so the patient can be cheerful.

With the important responsibility and a concern for litigation by non-Amish patients, several burn committees worked with a lawyer to develop a waiver. Some caregivers ask patients to sign this form, releasing them from the threat of a lawsuit if things do not go as planned.

\section{Decisive action then waiting to heal}

These caregivers were taught to take decisive action when a patient presented with a burn or wound. This included physical assessment, calling others for advice or assistance, making decisions about hospitalization, and skin grafting. Once an initial assessment was completed, they dealt with dressing changes, pain management, and nutrition. Several participants mentioned that they always took infants or young children for medical assessment if burns were greater than $10 \%$ of body surface for any degree of burns and if greater than $5 \%$ if any third degree burns. Sometimes the parents needed to be persuaded to go with the child to the hospital. One participant wrote,

Small children and infants present special concerns. Their bodies are small, and though the burn may not seem to be very large to us, fluid shifts can occur. These can lead to shock and cause death. "It was unexpected," we're told. The family didn't see it coming. "The child seemed fine."

After making sure the person is medically stable, caregivers stated that they cooled or verified that the burn had been adequately cooled. They prepared the B\&W and lathered it on the burdock leaves. Several explained their preference for this herbal-based treatment, including compassionate care, pain reduction, and less cost.

We use B\&W because it works. And it's pain free, and it's non-stick. And we never had infections. It's more compassionate than standard medical treatment. It's less painful, more comfortable for the patient. Non-stick, easier for the patient, very gentle.

There are many times when I dealt with children, and they were screaming, maybe when they came in, and once we were done, five minutes later, they were down. They were trying to play. There's nothing else like it. ... It's much more painful when you do it the conventional way. . . With B\&W you don't have to do the anesthesia.

One of the things that drives some of our beliefs, from way back when, is the money aspect of it. It creates a hardship. .. In a smaller community of a couple hundred people, and you give them a $\$ 100,000$ hospital bill - they're gonna hurt.

Several participants acknowledged that the use of B\&W ointment and burdock leaves does not heal burns faster than conventional treatments. But they accepted this so that they could care for their own. One man said, "The care part of it takes longer. And it's a different culture than what the rest of society is. We take care of our own people and it has to be a mutual respect on both sides I guess."

Conventional burn treatment includes debridement and skin grafting within a few days of the incident. The Amish community in general is resistant to skin grafting unless the burns are 
very extensive. They believe that skin grafts cause problems later. Many of the participants shared their opinions on this matter. One man said, "A skin graft is almost like, um, to some people, is like a swear word. Our theory is why graft if you can heal it naturally?" Another participant described tension between the Amish and medical community because of skin grafting.

One thing we run into is oftentimes, doctors in a burn unit tell us when to skin graft, and we think we can tell when we need to skin graft. So there's a little bit of a conflict in that. Skin grafts tighten up. It doesn't stretch. We're learning, learning more about how to massage. Everything's advancing. My personal opinion, if you have your own skin, and you can heal it, everything will work better. It's designed to work that way. The word I was looking for was 'crippling.' Because they had a bad case that they didn't want to skin graft, and they were forced to do it, and [the girl] couldn't, she finally couldn't even walk; because everything pulled so hard.

Another man explained their decisions about skin grafting this way.

I don't know if it's necessarily because of the conviction against skin grafting but more the results that we've been seeing, with the tying and the binding, restricting movement, and things like that. We wish we wouldn't have to do it, but it's not something that we would deny. I don't think, we wouldn't sacrifice a life because of, you know, it's not something that we would say 'absolutely no.'

When burns or wounds are new, caregivers change dressings at least every 12 hours. Caregivers believe that the B\&W ointment and burdock leaves gradually lose their efficacy, so frequent dressing changes are necessary for pain management and wound debridement. They also want to be aware of any delay in the healing process. One caregiver explained, "If you catch it head on, when it starts, and that's what we're referring to with the dressing every 12 hours, you can see stuff, if you know what you're looking for. It comes from experience for a trained eye." His wife added, "You should see a difference every time you take the dressing off. You will see a big difference if that body is healing, and the wound is healing."

They use a variety of distraction methods while doing dressing changes to help the patient be more comfortable. A mother or father often holds a child in her or his arms. One caregiver said,

The hands were burnt pretty bad and they were doing therapy, and the one was blowing bubbles, and playing with toys; anything to distract him from what we were actually doing. I often gave him his bottle and by the time we were done, he was sleeping.

Another caregiver spoke of distracting an elderly woman during her dressing changes.

This lady that was diabetic, I think it took so long to get the B\&W back on that it really started hurting again. And she just sometimes just couldn't handle it. So we took the girls along to sing. They just stood there and sang to her, just to keep her mind somewhere else. It helps. She even said that it helps.

During twice-daily dressing changes, the burn caregivers also stress the importance of proper nutrition to enhance healing. They advise patients and families to restrict high-sugar foods like cakes and cookies.

Get rid of the sugar. Not need the sugar, so the wounds heal better. We've seen it a time or two when they, when they started cheating a little bit and eating too much sugar and candy and while the wound [healing] slowed down. .. Desserts and things like that. 


\section{Self-reliance along with community collaboration}

Once the originators of the B\&W burdock treatment were convinced of its efficacy, they began to train family and community caregivers in regional workshops. Training sessions were held in several states to which people from each settlement were invited to attend. The trainees received a workbook and took notes, heard testimonials, saw demonstrations, and got hands-on experience doing dressing changes. They went home with supply kits. They gradually gained experience and were recognized by others as someone to call for help.

Amish and Mennonites do their utmost to care for each other, including families and neighbors, within the home. One participant said,

We just want to take care of our own people. We try to stay independent from the medical side as much as we can but we still need them. I like the back-up. We need, we need their expertise and their help in situations that we can't handle.

With caution, caregivers teach family members to continue the care of their children or other relatives, under advisement. "They usually just watch, and then they take over after that." One caregiver explained their caution. "We hesitate to train too many people because if you teach people and they do it on their own, then sooner or later somebody's going to mess up, try to be a hero or something."

Team members share the load when there is a difficult case or more than one case at a time.

We're trained because of experience. Everybody knows we can go to the hospital. There are caregivers that are trained to do the basics. And then if it gets over their head, that's where our team usually comes in or they call us for advice.

[In the past] I thought I had to cover for whatever got asked because people need help now. You can't say 'You have to wait until I'm not so busy.' They're hurt now. They're burned now. Now I don't have to do that anymore. If I've got a call from someone I don't know, or I feel overwhelmed, I can call the Burn Committee and say, "Find another caregiver."

Similar to the Amish church structure, these caregivers have no national organization or board of directors but several well-experienced Anabaptist caregivers are recognized as experts. Individual caregivers frequently phone those experts for advice. Caregiver committees organize regional meeting several times a year that serve as a time for debriefing and continuing education. One participant described what happened in his area. "It took a few years, but we did form meetings to keep us trained and keep us informed. We actually have a 3-man Board." Two participants voiced the need for and benefits of these meetings.

Those caregivers stood up and spoke, described what happened, how they took care of it, and then asked questions: what anybody else in the room thought they could have done different or should have done different. Everybody takes a turn and stands up and tells what they think. They have question boxes sent around and if somebody has a question, they put a question in. Then the members take it out and read it and then each that has experience, they'll explain how they did it.

I think it's very helpful. I mean, I couldn't do it without going through a meeting like that. Learning new things. There's always something new that somebody experienced, you know, not everybody's the same, so it is very helpful to learn. 
Caregivers also gather annually or bi-annually at daylong seminars. The day is organized by a board or committee to include singing, meals, visiting, and teaching. The attendees learn from case presentations, question and answer sessions, and guest speakers.

Members of the Amish community recognize that severely burned people need skin grafts to survive. But they also know that if the patient survives, extensive after-burn care is necessary. One physician, director of a hospital burn unit, told some caregivers of the need for after-burn care but admitted that massage therapy to prevent post-skin graft scarring and contractures was time consuming and very expensive to continue 45 minutes to an hour, three times a day, for a year. The Amish communities in several regions accepted the challenge. When a severely injured 5 -year old boy returned home, his community was ready. They had invited two communities to a meeting; about 40 people attended. Members of an After-Burn Care Board of another community demonstrated massage with oil therapy. One of the organizers once again described self-reliance with collaboration.

We're talking dedicated people. We got a calendar out that evening and people put down morning, noon, and evening so they have their times; every morning a certain time, noon at a certain time, and evenings a certain time. You know, that person is responsible. If he puts his name down for that day and something happens where he can't come, he has somebody else to replace him. That has to be it's not the parent's problem. This is gonna be the Community is gonna work with the parents to get this done.

\section{Treatment disallowed or negotiated support}

This theme centers on interactions between caregivers and health care professionals. Amish families and their burn caregivers have frequently experienced outright refusal from most physicians and nurses who will not agree to the use of B\&W and burdock leaf treatment in the hospital. Caregivers believe that refusal is usually because medical professionals lack familiarity with or understanding of the treatment, that B\&W ointment and burdock leaves lack FDAapproval; they fear subsequent infections, and are skeptical of the outcomes. One caregiver said,

Medical staff [in a hospital where I cared for patients] is fine with the salve. They have a problem with the leaves. Some have used seaweed bandages; the seaweed has been processed. [Of burdock leaves] they say, 'Absolutely no leaves.' They fear infection.

With their experience in providing this care, along with understanding the position of the medical staff, Amish have learned to advocate and negotiate for their patients. Families and caregivers have asked, begged, and pleaded for B\&W burdock treatment to be used, even to the point of taking patients out of the hospital against medical advice.

The family kept pushing them, 'Wouldn't you consider this, wouldn't you consider this?' 'No, no, no way.' The family kept on pushing - they want to try this, they want this. They were from [name of state], a small, conservative, Mennonite group. The family kept pushing and they had a couple there that had taken the caregiver's training, but didn't have much experience, which was not the issue. One day the doctor says, 'Are you serious about this?' 'Yeah.' 'Well then tomorrow morning you can start.'

Several hospitals require patients to sign a waiver. One has patients or families sign a 'Use of Own Medications Patient Agreement' form, allowing the lay caregivers to do dressing changes during hospitalization, with the understanding that the hospital will not be held responsible for complications. Other physicians have agreed to the treatment on a trial basis, a type of negotiated 
acknowledgement of the Amish community's desires. Acceptance has come gradually, usually when the physicians and nurses see the good results. Here's one example.

[Working with the doctor] in the ER. He didn't know about B\&W and told me I had to leave the leaves and everything off. We leave it off to transport. Dr. [name] wants to come in and watch everything that we do. That's very helpful. [In the past when] we had a patient, he looked at it and said, "Get that junk off or you're going to [another hospital]." And we ended up signing this kid against medical advice and taking care of it at home. And then we had [another] case, and this was the same doctor. I called down to that [other] caregiver and told her 'I'm not comfortable. You need to take her in, to have her checked out to see what's wrong." She had a low-grade urinary tract infection. But that doctor, he said, "You don't have to take it off - tell me if the burn looks okay. If you think it looks okay, I'm fine. And the caregiver said, 'It's fine.' So he didn't even take it off and look at it. That shows respect and confidence in us. That helps. I like that.

That example illustrates caregivers' deep desire is for mutual respect and support. They want to collaborate with the medical and nursing staff for the good of their patients. One participant said,

As far as the medical profession, you know, I respect them for what they are doing and it's not what they were trained in. They're doing what they were trained to. There's no doubt in my mind that they're ... I think I can kind of see what it may look like to them. I'm sure I don't realize it but still partially, you know. They've got their 7, 8, 10, 12 years of education - went into how much debt to get that education - and now a bunch of hillbillies come along and say it, it's not necessary. I can see that side of the story, how that would look to 'em. I think I can.

Caregivers recognize their limitations. They want to work alongside the medical staff.

It's a tremendous benefit if we could get them to a place where we could take the child the first 12-36 hours, with professional caretakers, as far as monitoring, not necessarily the wound but monitoring the, the uh, the stability of the child, of the body. Because that is one thing we don't know much about.

The caregivers who participated in this study are slowly seeing acceptance. Two participants' quotations illustrate progress.

It's very encouraging, how this has been going. I've heard [another caregiver] say, "If I would just have a little help. If I just had a little help from the medical society to help me." And I've been with a lot of meetings, with doctors, and you know, it's very encouraging. I've been with doctors that did like this. They didn't want anything to do with it. I've been with doctors that were very excited. They were so excited... We've had a lot of challenges. But there's always - it seems like somewhere there's an open mind.

Communication helps. If they listen to what we say and think we know something, if they respect our wishes - I'm not saying that we - that they need to let us do whatever we want to do - but respect our wishes and we find mutual ground between the two.

\section{Discussion}

Amish lay caregivers provide burns and wounds care with B\&W burdock dressings because of strong cultural values of caring for their own people (Farrar, Kulig, and SullivanWilson 2018; Fisher 2002; Girod 2002) and a preference for natural or holistic remedies (Gerdner, Trip-Reimer, and Sorofman 2002). Participants in this study described caregiving as personal commitment, community-focused care, and interactions with health care professionals. 
They experienced times of rewarding gratification as well as serious responsibility. Their involvement requires decisive action caring for new burns then patience during the healing process. They expressed their preference for self-reliance but recognized the importance of collaboration with other lay caregivers, family members, and health care professionals. They experienced physicians' refusal to accept the B\&W burdock treatment or negotiated with professionals for their support to use it.

These caregivers work within families in their districts, accept non-Amish patients from outside their settlements, and work with their severely injured patients under the supervision of medical and nursing staff in emergency rooms and during hospitalizations. As a rule, they treat burns that are less than $15 \%$ of body surface in their own homes or in the home of the injured person. They care for larger burns and wounds either in hospital, if acceptable to the hospital administration and physicians, or at home after assessment at the hospital. Important to the participants is working with family members to provide efficient and effective care. Decisionmaking will include parents, spouses, and elders (Armer and Radina 2006).

For many years, caregivers using the $\mathrm{B} \& \mathrm{~W}$ burdock leaf remedy have desired acceptance of their beliefs and practices by the professional health care community. They have worked humbly but determinedly to exhibit their own knowledge and skills while at the same time seeking the help of hospital staff in emergency rooms and burn units in several states in the US. Their wish is for medical supervision of their patients, including vital signs and hydration, while they provide wound care. They believe their treatment reduces the need for skin grafts, high doses of analgesics, and cost. Physicians, nurses, and other health care professionals who have listened to, and built relationships of mutual trust and respect with Amish patients and caregivers providing in-hospital care have in turn gained the respect of (Crawford, Manuel, and Wood 2009; Fisher 2002; Lee and Ruth-Sahd 2011) and the opportunity to treat the wider Amish community (Flurry, et al. 2017).

One of the reasons this population prefers to have things heal naturally is the financial burden incurred by hospital-related costs. Because of their beliefs about separation from the world and about self-sufficiency (Hurst and McConnell 2010), Amish do not subscribe to government health insurance plans. They pay cash for medical services. Therefore, when a hospital emergency department, hospitalization, or other biomedical interventions are required, the issue of finances is a part of the decision making process (King 2017). Mandal (2007) posited significant cost savings and convenience in the United Kingdom by the implementation of a home-based burn care program under the supervision of home care nurses. It included the use of telemedicine, digital photography, and email communication, plus outpatient surgery, when necessary, for debridement and skin grafting. The Amish already have such a system in place when using the $\mathrm{B} \& \mathrm{~W}$ burdock leaf treatment. All of the participants in this study have cell phone contacts with other team members and some with nearby physicians or nurses familiar with their methods and procedures. This has helped lay caregivers make decisions about the need for traveling to the hospital or modifying home care in some way, in many cases saving costs. Future research is needed to determine if this treatment along with the burn care team and community support actually reduces costs without compromising quality of care and recovery for burn victims.

Most of the burns and wounds treated with $\mathrm{B} \& \mathrm{~W}$ burdock described by participants in this study were minor in nature. Standards of care for severe burns involves wound excision and skin 
grafting within 10 days because of the likelihood of improved chances of survival, shortened hospital stays, better long-term outcomes, and reduced costs (Subcommittee 2016). Many members of the Amish community believe that skin grafting causes more pain and complications of contractures in comparison to their non-grafting treatment with B\&W and burdock leaves (Flurry, et al. 2017). Participants in this study preferred to not allow skin grafts because of scarring and contractures, particularly among children. They were willing to wait for healing 'naturally.' Their stance is similarly reported in several other articles (Kahn, Demme, and Lentz 2013; Main, Williams, and Jones 2012; Talpos 2015). Discussion and decisions surrounding the issue of skin grafting requires families, lay caregivers, and health care professionals listen to one another while weighing the risks and benefits of all factors.

In much of the literature on caring for burn patients, nurses describe the heavy emotional toll it takes to care for the severely burned (Haik, et al. 2017; Hilliard and O'Neill 2010; Kornhaber and Wilson 2011a; Negble, et al. 2014). The Amish and Mennonite participants in this study did not mention the high level of trauma, burnout, emotional distress, and compassion fatigue described in the above articles. Several caregivers did talk about having too many patients at once or worrying about making the right decisions for their patients. The lesser amount of emotional distress may be due to several factors. Most of the Amish caregivers' patients had minor burns, so dressing changes, observation, and supervision was only necessary for a few days or weeks. And none of their patients died. They did mention getting strength to provide care through their faith in God. If long-term care was necessary, most of the Amish caregivers worked as a team. In doing so, they spotted changes in a patient's condition. For example, irritability may indicate a poorly positioned dressing; a burn that is slow to heal may mean a lack of proper nutrition. Caregivers frequently phoned others who had more experience to ask for advice. These lay caregivers meet together on occasion to discuss how they could have done things differently, share photos of patients' progress, or describe their cases to less experienced caregivers. This collaboration serves as a type of debriefing similar to what Kornhaber and Wilson (2011b) found vitally important for nurses. A supportive workplace culture and meetings dedicated to sharing stories appear to sustain caregivers' attitudes and wellbeing and reduce stress (Haik, et al. 2017; Kornhaber and Wilson 2011b; Nagy 1999). As Amish caregivers seek to take care of more difficult cases over longer periods, including lengthy after-burn massage, they will need to consciously recognize that the physical, emotional, and spiritual burden may increase and learn how to deal with it. Teamwork, telemedicine, patient and family education, and interprofessional collaboration will strengthen the wellbeing of those who care for patients who have extended recovery time (Al-Mousawi, et al. 2009).

\section{Limitations and Strengths}

Limitations of this study include the fact that only the author analyzed the data. Therefore she returned to the 'field' with narrative data and themes and asked three Amish non-participant caregivers to express their opinions of the findings. They confirmed the author's themes with examples of their own. Strengths of this research include the lengthy participant observation of the researcher which increases the validity and credibility of the results. 


\section{Conclusion}

Amish and Mennonite lay caregivers described burns and wounds care in their communities as rewarding and challenging. They provide this care based on cultural values of caring for their own, using natural remedies to relieve suffering, and curbing costs where possible. While willing to work in difficult situations, these lay caregivers seek collaboration with family members and colleagues. They desire respect and understanding from health care professionals for their beliefs, values, and practices.

\section{References}

Al-Mousawi, Ahmed, Gabriel Mecott-Rivera, Marc Jeschke, and David Herndon. 2009. "Burn Teams and Burn Centers: The Importance of a Comprehensive Team Approach to Burn Care." Clinics in Plastic Surgery 36(4):547-54. https://doi.org/10.1016/j.cps.2009.05.015

Amish Burn Study Group, Nicole Kolacz, Mark Jaroch, Monica Bear, and Rosanna Hess. 2014. "The Effect of Burns \& Wounds (B\&W)/Burdock Leaf Therapy on Burn-Injured Amish Patients: A Pilot Study Measuring Pain Levels, Infection Rates, and Healing Times." Journal of Holistic Nursing 32(4):327-40. https://doi.org/10.1177/0898010114525683

Armer, Jane, and M. Elise Radina. 2002. "Definition of Health and Health Promotion Behaviors among Midwestern Amish Families." Journal of Multicultural Nursing \& Health 12(3):44-53.

Burn Certification List and Members of NHRG (Natural Health Research Group). 2008. Plain Interests. Millersburg, PA.

Chan, Yuk-Shing, Long-Ni Cheng, Jian-Hong Wu, Enoch Chan, Yiu-Wa Kwan, Simon Ming-Yuen Lee, George Pak-Heng Leung, Peter Hoi-Fu Yu, and Shun-Wan Chan. 2011. "A Review of the Pharmacological Effects of Arctium Lappa (Burdock).” Inflammopharmacology 19:245-54. https://doi.org/10.1007/s10787-010-0062-4

Crawford, Stephanie, Aimée Manuel, and Bruce Wood. 2009. "Pharmacists' Considerations when Serving Amish Patients." Journal of the American Pharmacists Association 49(1):86-94. https://doi.org/10.1331/JAPhA.2009.07160

Erdemoglu, Nurgun, Nilufer Turan, Esra Akkol, Bilge Sener, and Nurettin Abacioglu. 2009. "Estimation of Anti-Inflammatory, Antinociceptive and Antioxidant Activities on Arctium minus (Hill) Bernh. ssp. minus." Journal of Ethnopharmacology 121:318-23. https://doi.org/10.1016/j.jep.2008.11.009

Farrar, Helen, Judith Kulig, and Janet Sullivan-Wilson. 2018. "Older Adult Caregiving in an Amish Community." Research in Gerontological Nursing 11(1):29-38. https://doi.org/10.3928/1940492120171128-02

Fisher, Karen Kay. 2002. "Lessons Learned while Conducting Research within an Amish Community." Journal of Multicultural Nursing \& Health 8(3):21-28.

Flurry, Mitchell, Kelsie Herring, Logan Carr, Randy Hauck, and John Potochny. 2017. "Salve and Burdock: A Safe, Effective Amish Remedy for Treatment of Traumatic Wounds?" Advances in Skin \& Wound Care 30:213-17. https://doi.org/10.1097/01.ASW.0000515079.07160.e3

Fujita, Tetsuro, Ekrem Sezik, Mamoru Tabata, Erdem Yesilada, Gisho Honda, Yoshio Takeda, Toshihiro Tanaka, and Yoshihisa Takaishi. 1995. "Traditional Medicine in Turkey VII. Folk Medicine in Middle and West Black Sea Regions.” Economic Botany 49(4):406-22. https://doi.org/10.1007/BF02863092

Gerdner, Linda, Toni Tripp-Reimer, and Bernard Sorofman. 2002. "Health Beliefs and Practices: The Iowa Old Order Amish." Journal of Multicultural Nursing \& Health 8(3):65-72.

Girod, Jennifer. 2002. "A Sustainable Medicine: Lessons from the Old Order Amish.” Journal of Medical Humanities 23(1):31-42. https://doi.org/10.1023/A:1013037419428 
Haik, Josef, Stav Brown, Alon Liran, Denis Visentin, Amit Sokolov, Isaac Zilinsky, and Rachel Kornhaber. 2017. "Burnout and Compassion Fatigue: Prevalence and Associations among Israeli Burn Clinicians." Neuropsychiatric Disease and Treatment 13:1533-40. https://doi.org/10.2147/NDT.S133181

Hilliard, Carol, and Mary O'Neill. 2010. "Nurses' Emotional Experience of Caring for Children with Burns.” Journal of Clinical Nursing 19(19-20):2907-15. https://doi.org/10.1111/j.13652702.2009.03177.x

Hurst, Charles, and David McConnell. 2010. An Amish Paradox: Diversity and Change in the World's Largest Amish Community. Baltimore, MD: Johns Hopkins University Press.

Kahn, Steven, Richard Demme, and Christopher Lentz. 2013. "Mortality after Treating Severe Burns with Traditional Amish Home Remedies: A Case Report, Literature Review, and Ethical Discussion." Burns 39(2):e13-e16. https://doi.org/10.1016/j.burns.2012.09.011

King, Martha. 2017. "Crafting an Amish Biomedical Landscape.” Medicine Anthropology Theory 4(1):105-22. https://doi.org/10.17157/mat.4.1.365

Kornhaber, Rachel, and Anne Wilson. 2011a. "Enduring Feelings of Powerlessness as a Burns Nurse: A Descriptive Phenomenological Inquiry." Contemporary Nurse 39(2):172-79. https://doi.org/10.5172/conu.2011.172

Kornhaber, Rachel, and Anne Wilson. 2011b. "Psychosocial Needs of Burns Nurses: A Descriptive Phenomenological Inquiry." Journal of Burn Care \& Research 32:286-93. https://doi.org/10.1097/BCR.0b013e31820aaf37

Lee, Yuri Anna, and Lisa Ruth-Sahd. 2011. "When the East Meets the Amish: An Application of Folk Medicine in the Amish Community." Journal of Lancaster General Hospital 6(3):114-18.

Lou, Zaixiang, Hongxin Wang, Wenping Lu, Chaoyang Ma, Zhouping Wang, and Shangwei Chen. 2010. "Assessment of Antibacterial Activity of Fractions from Burdock Leaf against Food-Related Bacteria." Food Control 21(9):1272-78. https://doi.org/10.1016/j.foodcont.2010.02.016

Main, M. Eve, Deborah Williams, and Myra Jones. 2012. "Treatment of Burns with Burns \& Wounds (B \& W) Ointment and Leaf Therapy." Journal of Alternative and Complementary Medicine 18(2):10911. https://doi.org/10.1089/acm.2011.0416

Mandal, Anirban. 2007. "Quality and Cost-Effectiveness-Effects in Burn Care." Burns 33:414-17. Anirban. 2007. "Quality and Cost-Effectiveness_Effects in Burn Care." Burns 33:414-17. https://doi.org/10.1016/j.burns.2006.08.035

Nagy, Sue. 1999. "Strategies Used by Burns Nurses to Cope with the Infliction of Pain on Patients." Journal of Advanced Nursing 29(6):1427-33. https://doi.org/10.1046/j.1365-2648.1999.01030.x

Negble, M, P Agbenorku, E Ampomah, and P. Hoyte-Williams. 2014. "Nursing Severe Burn Injury Patients: Emotional Impact on Nurses." International Journal of Medicine and Medical Sciences 47(1):1430-33.

Polit, Denise, and Cheryl Beck. 2012. Nursing Research: Generating and Assessing Evidence for Nursing Practice. Philadelphia, PA: Wolters Kluwer|Lippincott Williams \& Wilkins.

Subcommittee, Steering, Advisory Subcommittee, and ISBI Practice Guidelines Committee. "ISBI Practice Guidelines for Burn Care." Burns 42:953-1021.

Talpos, Sara. 2015. "Seeking Common Ground: UMHS Works with Amish and Mennonite Communities toward a Culturally Sensitive Approach to Burn Treatment." Medicine at Michigan 17(2):30-35. (http://www.medicineatmichigan.org/archive/2015/summer)

Trinkle, Krystal Melich. 2016. "Amish Culture and Their Utilization of Burns and Wounds Ointment for the Treatment of Burns." Holistic Nursing Practice 30(2):78-87. https://doi.org/10.1097/HNP.0000000000000133 